\title{
The Influence on Modal Parameters of Thin Cylindrical Shell under Bolt Looseness Boundary
}

\author{
Hui Li, Mingwei Zhu, Zhuo Xu, Zhuo Wang, and Bangchun Wen \\ School of Mechanical Engineering and Automation, Northeastern University, No. 3-11 Wenhua Road, Heping District, \\ Shenyang 110819, China \\ Correspondence should be addressed to Hui Li; lh200300206@163.com
}

Received 20 July 2015; Revised 3 October 2015; Accepted 5 October 2015

Academic Editor: Daniel Morinigo-Sotelo

Copyright (C) 2016 Hui Li et al. This is an open access article distributed under the Creative Commons Attribution License, which permits unrestricted use, distribution, and reproduction in any medium, provided the original work is properly cited.

\begin{abstract}
The influence on modal parameters of thin cylindrical shell (TCS) under bolt looseness boundary is investigated. Firstly, bolt looseness boundary of the shell is divided into two types, that is, different bolt looseness numbers and different bolt looseness levels, and natural frequencies and mode shapes are calculated by finite element method to roughly master vibration characteristics of TCS under these conditions. Then, the following measurements and identification techniques are used to get precise frequency, damping, and shape results; for example, noncontact laser Doppler vibrometer and vibration shaker with excitation level being precisely controlled are used in the test system; "preexperiment" is adopted to determine the required tightening torque and verify fixed constraint boundary; the small-segment FFT processing technique is employed to accurately measure nature frequency and laser rotating scanning technique is used to get shape results with high efficiency. Finally, based on the measured results obtained by the above techniques, the influence on modal parameters of TCS under two types of bolt looseness boundaries is analyzed and discussed. It can be found that bolt looseness boundary can significantly affect frequency and damping results which might be caused by changes of nonlinear stiffness and damping and in bolt looseness positions.
\end{abstract}

\section{Introduction}

Thin cylindrical shell (TCS) has long been an important structural component due to its high stiffness to weight and strength to weight ratios, which is widely used in the engineering fields, such as aircraft casings, pipes and ducts, rotary drums in granulator, and aircraft engine [1-5]. Modal parameters of TCS are mainly composed of natural frequencies, mode shapes, and damping ratio; these parameters are the basis of further study on vibration characteristics of TCS [6-8], which are of great importance to theoretical modeling, response prediction, vibration reduction optimization, vibration mechanism research, structural damage identification, and so forth. Generally, TCS is working at a very harsh environment, such as thermal expansion and contraction, strong vibration, and uneven exciting force generated by turbulent air flow, which may easily make TCS operate under elasticity or looseness boundary [9]. Besides, due to different installation forms, the connected or constraint end of TCS may not be well fixed [10]. For example, if TCS is connected or constrained by many bolts, its constraint effectiveness will inevitably be weakened under complex external load [11, 12], especially when a bolt or some bolts come loose; the looseness condition will not only decrease constraint strength but also increase interface abrasion and the probability of fatigue failure, and, once the bolt fracture happens, it will severely affect the function of TCS and could even lead to serious accident [13].

At present great efforts have been made to study vibration character of TCS under complex and diverse boundary condition by scholars and researchers, for example, bolt looseness, elasticity, and other complex boundary conditions, and many encouraging research results have been obtained. For example, Forsberg [14] studied the influence of boundary conditions on the modal characteristics of thin cylindrical shells. Totally 16 possible sets of homogeneous boundary conditions were specified independently at each end of the shell, and these sets of conditions were discussed in detail. It has been found that even for long cylinders (length to radius ratio of 40 or more) the minimum natural frequency may 
differ by more than $50 \%$ depending upon whether $u=0$ or the longitudinal stress resultant $N x=0$ at both ends. Koga [15] studied the effects of boundary conditions on the free vibrations of TCS and a simple formula for the natural frequency was derived as an asymptotic solution for the eigenvalue problems of the breathing vibrations, whose accuracy was sequentially examined by a comparison with numerical solutions and experimental results. The results showed that the formula was accurate enough for engineering and it was applicable under any possible combinations of the boundary conditions for the simply supported, the clamped, and the free ends of the shell. Sofiyev et al. [16] proposed an analytical procedure to study the free vibration characteristics of laminated thin circular cylindrical shells resting on elastic foundation. They found that natural frequency was as a function of the shell displacement amplitude, and it was also close related to the effect of elastic foundation, nonlinearity, and number and ordering of layers of the shell. Liang and Zhang [17] studied stiffness optimization of TCS under elasticity boundary condition. The explicit formula of initial parameter solution of variable thickness shell was derived by transfer matrix method, and the optimization process was transformed into a constraint nonlinear solving process; thus the objective function can be successfully obtained by the stepped reduction method. Dong et al. [18] investigated the influences of bolt looseness in missile clamping support on vibration characteristics of the cylindrical shell structure by base excitation technique. Different steady response signals were obtained by varying bolt pretightening force of the attachment bolts in the structure, and power spectrum density diagrams of signals corresponding to different status of the structure were analyzed and an extraction method of the spectral moment looseness was proposed to distinguish fault characteristics of bolt looseness. Dong et al. [19] also experimentally studied how to monitor the attachment bolt looseness in a clamped cylindrical shell structure, and wavelet transform was used to analyze damage characteristic of bolt looseness based on the structural acceleration response data. Zhou et al. [20] used the wave propagation method to solve the equations of motion of TCS under elastic-support boundary condition, and the elastic-support boundary condition was specified in terms of 8 independent sets of distributed springs which have arbitrary stiffness values. Besides, the effects on nature frequencies of the restraining springs were also studied for a range of stiffness values and different geometrical characteristics of the shells, and it was found that the restraining stiffness can drastically affect frequency parameters of TCS. Sun [21] used transfer matrix method to study the free vibration of TCS under elasticity boundary condition, taking into account elastic connection stiffness, and the transfer matrix of global variables of TCS under elasticity boundary condition was obtained by multiplying transfer matrix of state variables in the connection boundary with the one of the shell itself.

However, most of researches done by the above scholars and researchers are mainly based on theory or simulation; experimental studies on the influence on modal parameters of TCS under bolt looseness boundary (BLB) are still scarce. And as a lack of the related test conclusion, theoretical analysis results of the shell under more complex boundary condition can not be effectively verified, let alone validate some advanced shell theories.

This research combined theory with experiment to investigate the influence on modal parameters of TCS under BLB. Firstly, bolt looseness boundary of the shell is divided into two types, that is, different bolt looseness numbers and different bolt looseness levels, and natural frequencies and mode shapes of TCS under these conditions are calculated by finite element method (FEM) in Section 2; thus vibration characteristics of TCS under the above two types of bolt looseness boundaries can be roughly mastered. Then we go on to set up experiment system to accurately measure modal parameters of TCS, and the corresponding test procedures and identification techniques which are suitable for the thin walled shell are also proposed in Section 3. Finally in Section 4, based on the accurate measured data, the influence on natural frequencies, mode shapes, and damping ratios of TCS under two types of bolt looseness boundaries is analyzed and discussed in details. This research can provide dynamic modeling service for TCS under complex boundary condition, provide experimental data for effective selection of boundary parameters in the theoretical model, and also provide an important reference for analysis and diagnosis of bolt looseness fault of TCS.

\section{Vibration Characteristic Analysis of TCS under Bolt Looseness Boundary}

In this section, in order to deeply understand vibration characteristic of TCS, FEM is used to calculate vibration characteristic of TCS, such as natural frequencies and mode shapes, under two types of bolt looseness boundaries with different looseness numbers and different looseness levels, respectively. Although the resulting frequencies and shapes may inevitably contain some calculation errors, they are helpful for us to determine measured frequency range, build experimental model, understand geographic distributions of some nodes or nodal lines, and so forth.

2.1. Research Object. The TCS studied in this paper is shown in Figure 1 and dimension parameters are listed in Table 1. The material of TCS is structural steel with elastic modulus of $212 \mathrm{Gpa}$, Poisson's ratio of 0.3 , and the density of $7850 \mathrm{~kg} / \mathrm{m}^{3}$. Its length is $95 \mathrm{~mm}$ with $144 \mathrm{~mm}$ external radius and an average thickness of $2 \mathrm{~mm}$. There is the extension edge with $150 \mathrm{~mm}$ external radius and $3 \mathrm{~mm}$ thickness on this shell which is machined to be clamped by a clamping-ring with eight M8 bolts, so that it can be certain that the shell is in cantilever boundary condition. Then, we can loosen some or all of bolts with certain tightening torque by torque wrench, so that we can analyze vibration characteristic of TCS under bolt looseness boundary.

\subsection{Vibration Characteristic Analysis of TCS under BLB with} Different Looseness Numbers. Finite element model of the TCS under BLB with different looseness numbers is established with ANSYS Parametric Design Language (APDL) in 

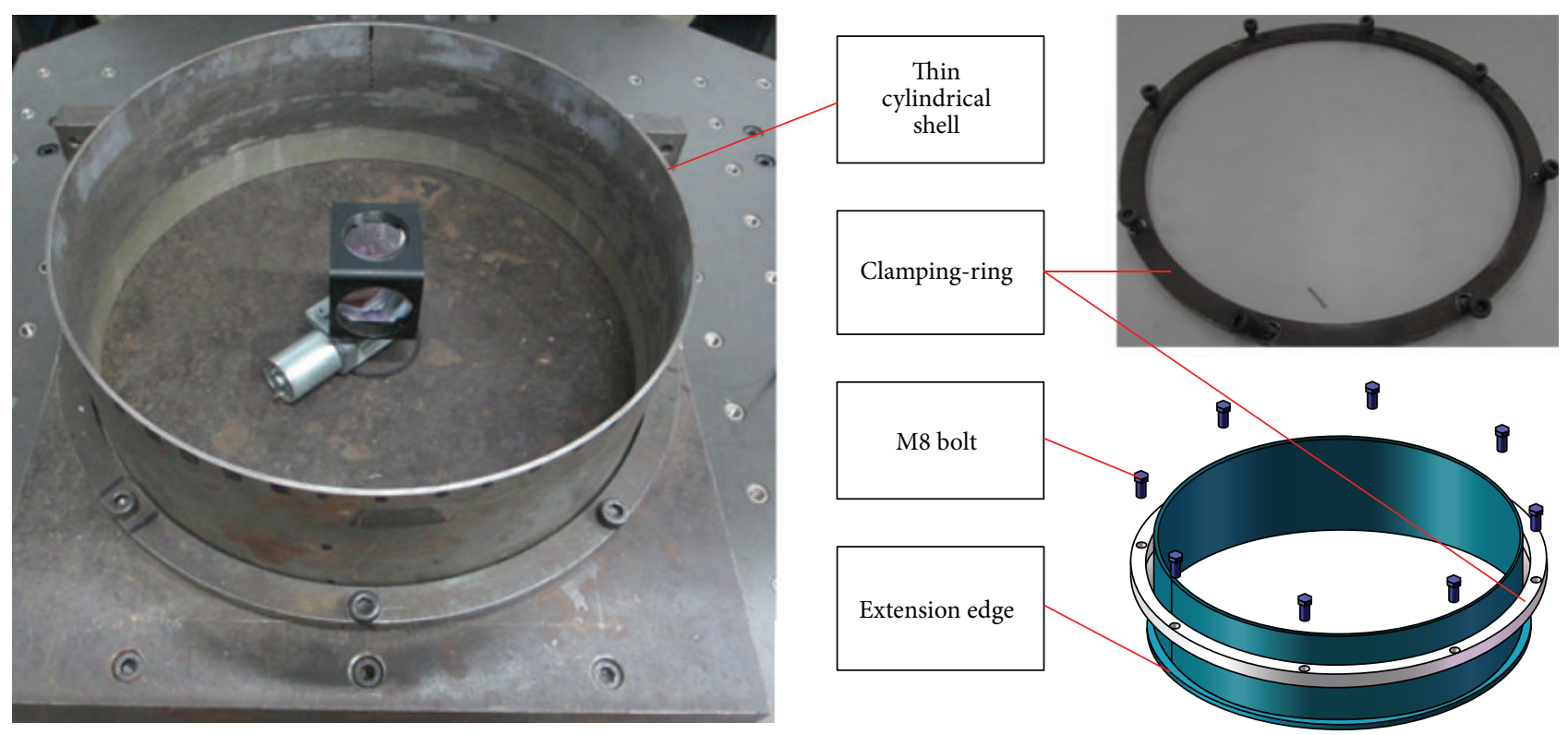

FIGURE 1: TCS and its clamped circular ring used in bolt looseness boundary.

TABLE 1: Dimension parameters of thin cylindrical shell.

\begin{tabular}{lcccc}
\hline $\begin{array}{l}\text { Length } \\
(\mathrm{mm})\end{array}$ & $\begin{array}{c}\text { Thickness } \\
(\mathrm{mm})\end{array}$ & $\begin{array}{c}\text { Internal radius } \\
(\mathrm{mm})\end{array}$ & $\begin{array}{c}\text { External radius } \\
(\mathrm{mm})\end{array}$ & $\begin{array}{c}\text { Extension edge radius } \\
(\mathrm{mm})\end{array}$ \\
\hline 95 & 2 & 142 & 144 & $\begin{array}{c}\text { Thickness of } \\
\text { extension edge } \\
(\mathrm{mm})\end{array}$ \\
\hline
\end{tabular}

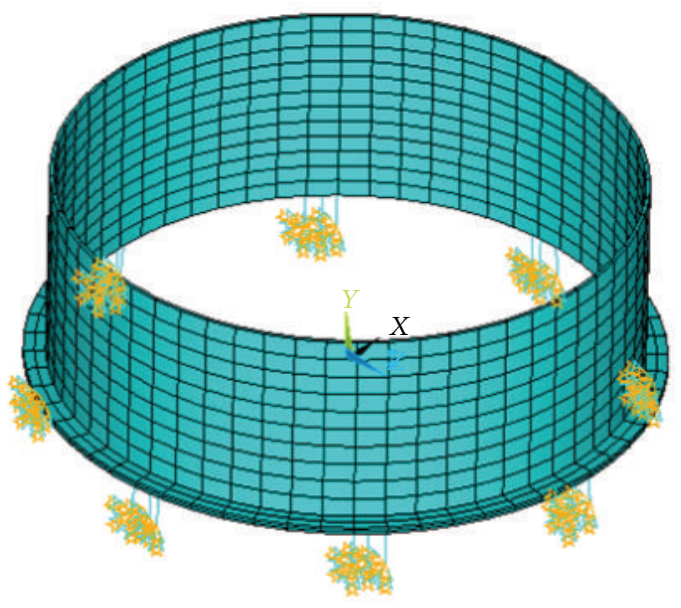

Figure 2: Finite element model of the TCS under BLB with different looseness numbers.

ANSYS software, as seen in Figure 2. SOLID186 element is used to create the model of the shell which consists of 6480 nodes and 960 elements, and MATRIX27 element is used as spring element to simulate bolt looseness boundary with different looseness numbers, whose stiffness can be adjusted in the $x, y$, and $z$ direction. Firstly, use 8 spring elements with stiffness value of $1 \times 10^{8}$ in the above three directions to simulate the free-clamped boundary condition, and the resulting natural frequencies and mode shapes are obtained by Block Lanczos method, as listed in Tables 2 and 3, respectively. Then, use different numbers of spring elements to simulate different bolt looseness numbers and calculate the corresponding frequencies and shape results, according to the sequence of loosening 1 bolt, 2 bolts, 3 bolts, and 4 bolts, from sequence I to sequence IV as shown in Figure 3, and the calculated results are given in Table 2 and Table 3. Additionally, the frequencies differences under the constraint boundary (or no loose boundary) and bolt looseness boundary with different looseness numbers are also compared in Table 2, and Figure 4 gives the relations between natural frequency and mode shape under BLB with different looseness numbers. It should be noted that, due to the specificity of the first mode shape, it is difficult to use traditional number of axial half-waves, $m$, and circumferential waves, $n$, to describe its vibration shape; thus the first special frequency and shape result are not compared under BLB in Table 2 (the calculated results are only for roughly understanding vibration characteristic of TCS when the constraint bolts are loose; they inevitably contain some calculation errors because constraint stiffness and damp parameters in bolt looseness positions are hard to simulate without experimental test, and they are not the focus of this paper).

It can be found from the above analysis results in Tables 2 and 3 and Figure 4 that (I) bolt looseness will result in the decrease of natural frequencies of TCS, and with the increasing of bolt looseness numbers the frequency results will further decrease; (II) high order natural frequencies of 
TABLE 2: Natural frequencies of TCS under BLB with different looseness numbers.

\begin{tabular}{|c|c|c|c|c|c|c|c|c|c|}
\hline $\begin{array}{l}\text { Modal } \\
\text { order }\end{array}$ & $\begin{array}{c}\text { No looseness } \\
A \\
(\mathrm{~Hz})\end{array}$ & $\begin{array}{c}\text { Loosen } \\
1 \text { bolt } \\
B \\
(\mathrm{~Hz}) \\
\end{array}$ & $\begin{array}{c}\text { Difference I } \\
(B-A) / A \\
(\%)\end{array}$ & $\begin{array}{c}\text { Loosen } \\
2 \text { bolts } \\
C \\
(\mathrm{~Hz}) \\
\end{array}$ & $\begin{array}{c}\text { Difference II } \\
(C-A) / A \\
(\%)\end{array}$ & $\begin{array}{c}\text { Loosen } \\
3 \text { bolts } \\
D \\
(\mathrm{~Hz}) \\
\end{array}$ & $\begin{array}{c}\text { Difference } \\
\text { III } \\
(D-A) / A \\
(\%) \\
\end{array}$ & $\begin{array}{c}\text { Loosen } \\
4 \text { bolts } \\
E \\
(\mathrm{~Hz}) \\
\end{array}$ & $\begin{array}{c}\text { Difference } \\
\text { IV } \\
(E-A) / A \\
(\%)\end{array}$ \\
\hline 1 & - & 786.2 & - & 678.0 & - & 591.9 & - & 554.4 & - \\
\hline 2 & 976.5 & 974.2 & -0.2 & 935.0 & -4.3 & 831.6 & -14.8 & 758.9 & -22.3 \\
\hline 3 & 1068.7 & 1065.0 & -0.3 & 1043.2 & -2.4 & 1035.4 & -3.1 & 1013.0 & -5.2 \\
\hline 4 & 1313.8 & 1298.5 & -1.2 & 1248.4 & -5.0 & 1193.3 & -9.2 & 1146.8 & -12.7 \\
\hline 5 & 1535.9 & 1461.0 & -4.9 & 1310.0 & -14.7 & 1275.1 & -17.0 & 1269.0 & -17.4 \\
\hline 6 & 1603.2 & 1597.6 & -0.3 & 1629.0 & 1.6 & 1591.1 & -0.8 & 1403.4 & -12.5 \\
\hline 7 & 1841.9 & 1743.4 & -5.3 & 1681.1 & -8.7 & 1655.8 & -10.1 & 1588.3 & -13.8 \\
\hline 8 & 2000.8 & 1995.6 & -0.3 & 1991.7 & -0.5 & 1988.0 & -0.6 & 1984.9 & -0.8 \\
\hline
\end{tabular}

TABLE 3: Mode shapes of TCS under BLB with different looseness numbers.

\begin{tabular}{|c|c|c|c|c|c|}
\hline $\begin{array}{l}\text { Modal } \\
\text { order }\end{array}$ & $\begin{array}{c}\text { No looseness } \\
A(m, n)\end{array}$ & $\begin{array}{c}\text { Loosen } \\
1 \text { bolt } \\
B(m, n)\end{array}$ & $\begin{array}{c}\text { Loosen } \\
2 \text { bolts } \\
C(m, n)\end{array}$ & $\begin{array}{c}\text { Loosen } \\
3 \text { bolts } \\
D(m, n)\end{array}$ & $\begin{array}{c}\text { Loosen } \\
4 \text { bolts } \\
E(m, n)\end{array}$ \\
\hline 1 & - & (Special) & (Special) & (Special) & (Special) \\
\hline 2 & $(1,5)$ & $(1,5)$ & $(1,5)$ & $(1,5)$ & $(1,5)$ \\
\hline 3 & $(1,6)$ & $(1,6)$ & $(1,6)$ & $(1,6)$ & $(1,6)$ \\
\hline 4 & $(1,7)$ & $(1,7)$ & $(1,4)$ & $(1,4)$ & $(1,4)$ \\
\hline 5 & $(1,4)$ & $(1,4)$ & $(1,7)$ & $(1,7)$ & $(1,7)$ \\
\hline 6 & $(1,8)$ & $(1,8)$ & $(1,8)$ & $(1,8)$ & $(1,3)$ \\
\hline 7 & $(1,3)$ & $(1,3)$ & $(1,3)$ & $(1,3)$ & $(1,8)$ \\
\hline 8 & $(1,9)$ & $(1,9)$ & $(1,9)$ & $(1,9)$ & $(1,9)$ \\
\hline
\end{tabular}

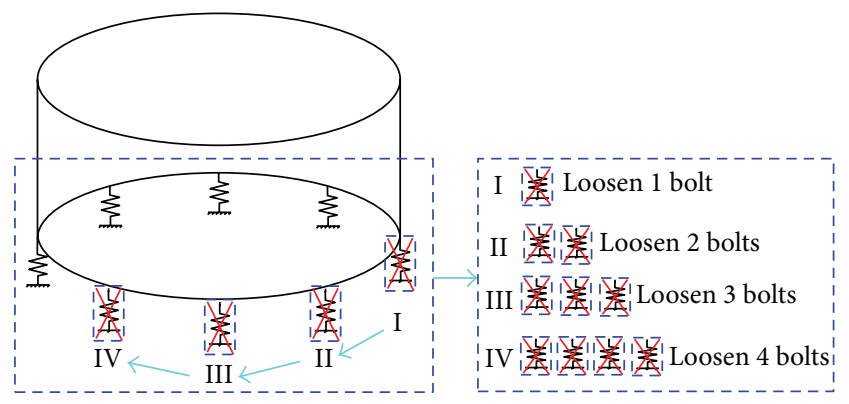

FIGURE 3: Schematic of bolt loosening sequence under BLB with different looseness numbers.

the shell, for example, the 8th natural frequency, basically will not be affected by BLB with different looseness numbers, and the frequency difference related to the BLB and no loose condition is less than $0.8 \%$; (III) with the increase of bolt looseness number, low order mode shapes of TCS will be changed, but high order mode shapes will still be unchanged; (IV) although frequencies and shapes of TCS will be changed under BLB, the changing trend of natural frequencies with mode shapes is constant when the number of axial half-waves $m=1$, which shows that frequency values are up after the decline with the increase of the number of circumferential waves $n$, and usually frequency values related to $n>8$ are higher than $n=2 \sim 7$.

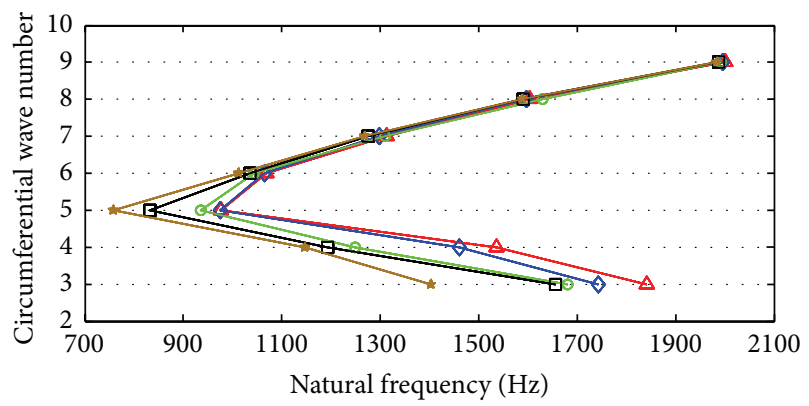

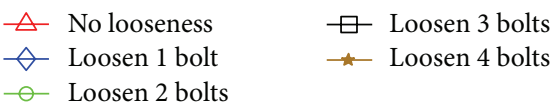

FIgURE 4: The relation between natural frequency and mode shape under BLB with different looseness numbers.

2.3. Vibration Characteristic Analysis of TCS under BLB with Different Looseness Levels. Similarly, SOLID186 element is used to create the model of the shell which consists of 6480 nodes and 960 elements, and MATRIX27 element is used as spring element to simulate bolt looseness boundary with different looseness levels; for example, set the stiffness value of Matrix27 element in $x, y$, and $z$ direction to $0.75 \times 10^{8}$, $0.25 \times 10^{8}$, and $0.25 \times 10^{7}$, respectively (namely, $25 \%$ looseness, 75\% looseness, and 97.5\% looseness), as seen in Figure 5. 
TABLE 4: Natural frequencies of TCS under BLB with different looseness levels.

\begin{tabular}{|c|c|c|c|c|c|c|c|}
\hline $\begin{array}{l}\text { Modal } \\
\text { order }\end{array}$ & $\begin{array}{c}\text { No looseness } \\
A \\
(\mathrm{~Hz})\end{array}$ & $\begin{array}{c}25 \% \\
\text { looseness } \\
B \\
(\mathrm{~Hz}) \\
\end{array}$ & $\begin{array}{c}\text { Difference I } \\
(B-A) / A \\
(\%)\end{array}$ & $\begin{array}{c}75 \% \\
\text { looseness } C \\
(\mathrm{~Hz})\end{array}$ & $\begin{array}{c}\text { Difference } \\
\text { II } \\
(C-A) / A \\
(\%) \\
\end{array}$ & $\begin{array}{c}97.5 \% \\
\text { looseness } \\
D \\
(\mathrm{~Hz}) \\
\end{array}$ & $\begin{array}{c}\text { Difference } \\
\text { III } \\
(D-A) / A \\
(\%)\end{array}$ \\
\hline 1 & - & 965.2 & - & 940.8 & - & 858.1 & - \\
\hline 2 & 976.5 & 973.2 & -0.3 & 956.0 & -2.1 & 898.6 & -8.0 \\
\hline 3 & 1068.7 & 1067.4 & -0.1 & 1056.0 & -1.2 & 1035.4 & -3.1 \\
\hline 4 & 1313.8 & 1312.9 & -0.1 & 1308.9 & -0.4 & 1293.1 & -1.6 \\
\hline 5 & 1535.9 & 1530.7 & -0.3 & 1504.3 & -2.1 & 1382.8 & -10.0 \\
\hline 6 & 1603.2 & 1602.8 & 0 & 1601.5 & -0.1 & 1594.9 & -0.5 \\
\hline 7 & 1841.9 & 1835.4 & -0.4 & 1802.5 & -2.1 & 1650.2 & -10.4 \\
\hline 8 & 2000.8 & 2000.5 & 0 & 1999.3 & -0.1 & 1993.5 & -0.4 \\
\hline
\end{tabular}

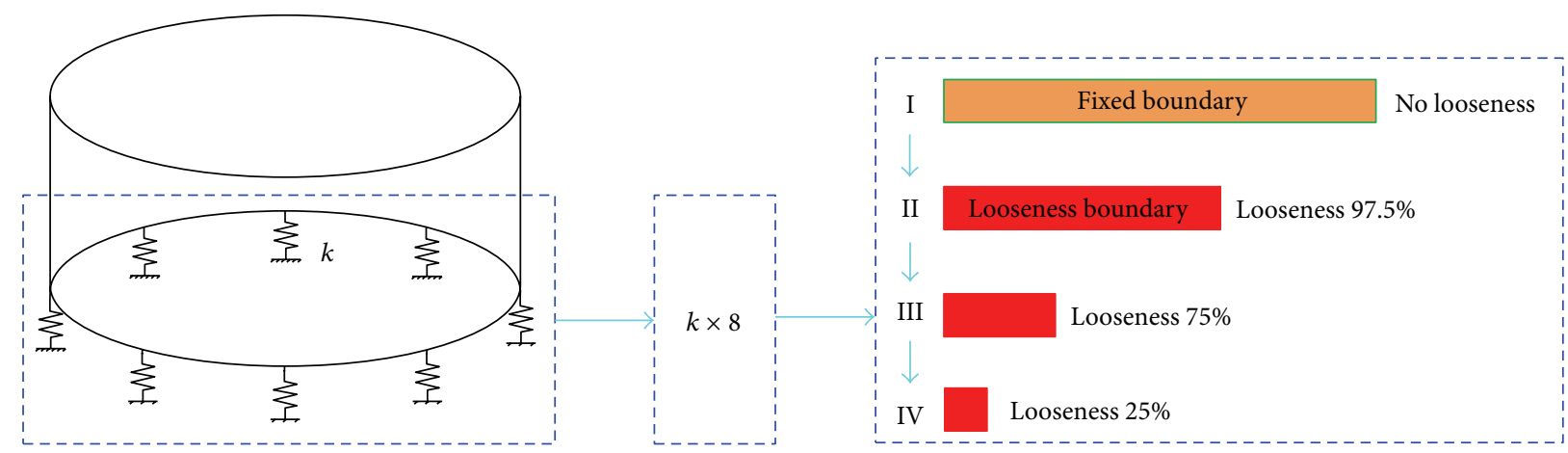

FIGURE 5: Schematic of different bolt looseness level adopted by FEM.

TABLE 5: Mode shapes of TCS under BLB with different looseness levels.

\begin{tabular}{lcccc}
\hline $\begin{array}{l}\text { Modal } \\
\text { Order }\end{array}$ & $\begin{array}{c}\text { No looseness } \\
(m, n)\end{array}$ & $\begin{array}{c}25 \% \\
\text { looseness } \\
B(m, n)\end{array}$ & $\begin{array}{c}75 \% \\
\text { looseness } \\
C(m, n)\end{array}$ & $\begin{array}{c}97.5 \% \\
\text { looseness } \\
D(m, n)\end{array}$ \\
\hline 1 & - & $($ Special $)$ & $($ Special $)$ & $($ Special $)$ \\
2 & $(1,5)$ & $(1,5)$ & $(1,5)$ & $(1,5)$ \\
3 & $(1,6)$ & $(1,6)$ & $(1,6)$ & $(1,6)$ \\
4 & $(1,7)$ & $(1,7)$ & $(1,7)$ & $(1,4)$ \\
5 & $(1,4)$ & $(1,4)$ & $(1,4)$ & $(1,3)$ \\
6 & $(1,8)$ & $(1,8)$ & $(1,8)$ & $(1,7)$ \\
7 & $(1,3)$ & $(1,3)$ & $(1,3)$ & $(1,8)$ \\
8 & $(1,9)$ & $(1,9)$ & $(1,9)$ & $(1,9)$ \\
\hline
\end{tabular}

Firstly, use 8 spring elements with stiffness value of $1 \times$ $10^{8}$ in above three directions to simulate the free-clamped boundary condition, and the resulting natural frequencies and mode shapes are obtained by Block Lanczos method, as listed in Tables 4 and 5. Then, use $0.75 \times 10^{8}, 0.25 \times 10^{8}$, and $0.25 \times 10^{7}$ of 8 spring elements to simulate different bolt looseness levels, according to the sequence of $25 \%$ looseness, $75 \%$ looseness, and $97.5 \%$ looseness to calculate the corresponding frequencies and shape results, from sequence I to sequence III as shown in Figure 5, which are also given in Tables 4 and 5. Additionally, the frequencies differences

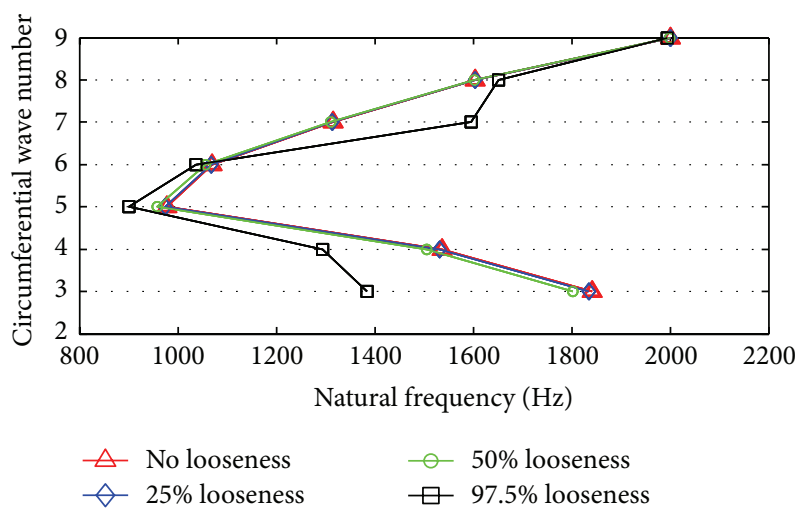

FIGURE 6: The relation between natural frequency and mode shape under BLB with different looseness levels.

under the constraint boundary (or no loose boundary) and bolt looseness boundary with different looseness levels are also compared in Table 4, and Figure 6 gives the relations between natural frequency and mode shape under BLB with different looseness levels.

It can be found from the above analysis results in Tables 4 and 5 and Figure 6 that (I) bolt looseness will result in the decrease of natural frequencies of TCS, and with the increasing of bolt looseness levels the frequency results will further decrease; (II) high order natural frequencies of the 
TABLE 6: The disadvantages of different vibration excitation devices for modal test of TCS under under bolt looseness boundary.

\begin{tabular}{|c|c|c|c|c|}
\hline \multirow{2}{*}{$\begin{array}{l}\text { Excitation } \\
\text { device }\end{array}$} & \multicolumn{3}{|c|}{ Modal parameters of TCS } & \multirow[b]{2}{*}{ Disadvantage } \\
\hline & $\begin{array}{c}\text { Natural } \\
\text { frequency }\end{array}$ & $\begin{array}{l}\text { Mode } \\
\text { shape }\end{array}$ & Damping ratio & \\
\hline Hammer & $\sqrt{ }$ & $\sqrt{ }$ & $x$ & $\begin{array}{l}\text { Pulse excitation level can not be } \\
\text { precisely controlled and the } \\
\text { excitation force varies for each } \\
\text { measurement, and double hit can } \\
\text { often lead to test errors. }\end{array}$ \\
\hline $\begin{array}{l}\text { Electromagnetic } \\
\text { exciter }\end{array}$ & $x$ & $x$ & $x$ & $\begin{array}{l}\text { The related force sensor will } \\
\text { bring added mass and stiffness to } \\
\text { TCS, which will severely affect } \\
\text { test results of damping and } \\
\text { natural frequency. }\end{array}$ \\
\hline $\begin{array}{l}\text { Piezoelectric } \\
\text { ceramic exciter }\end{array}$ & $\sqrt{ }$ & $\sqrt{ }$ & $x$ & $\begin{array}{l}\text { The excitation energy of } \\
\text { piezoelectric ceramic exciter is } \\
\text { often insufficient for TCS, which } \\
\text { will result in poor response } \\
\text { signal with low level of signal } \\
\text { noise ratio. }\end{array}$ \\
\hline Vibration shaker & $\sqrt{ }$ & $\sqrt{ }$ & $\sqrt{ }$ & $\begin{array}{l}\text { Excitation frequencies are not } \\
\text { that high, which are often limited } \\
\text { to } 1 \mathrm{~Hz} 3000 \mathrm{~Hz} \text {, and the test } \\
\text { procedures are often } \\
\text { complicated. }\end{array}$ \\
\hline
\end{tabular}

shell, for example, the 8th natural frequency, basically will not be affected by BLB with different looseness levels, and the frequency difference related to the BLB and no loose condition is less than $0.4 \%$; (III) with the increase of bolt looseness levels, low order mode shapes of TCS will be changed, but high order mode shapes will still be unchanged; (IV) although frequencies and shapes of TCS will be changed under BLB, the changing trend of natural frequencies with mode shapes is constant when the number of axial half-waves $m=1$, which shows that frequency values are up after the decline with the increase of the number of circumferential waves $n$, and usually frequency values related to $n>8$ are higher than $n=2 \sim 7$.

\section{Test System and Method of Modal Parameters of TCS under Bolt Looseness Boundary}

In Section 2, vibration characteristic of TCS under BLB and its influence is analyzed. But due to the complexity of bolt looseness boundary, the real influence of such boundary on modal parameters, especially the damping characteristics of the shell can not be accurately analyzed by simulation method. Therefore, it is necessary to employ experimental test to investigate on the influence on modal parameters of bolt constrained shell under different looseness boundaries. In this section, experiment system is firstly established to accurately measure modal parameters of the shell, and the corresponding test procedures and identification techniques which are suitable for the thin walled shell are also proposed.
3.1. Test System of Modal Parameters of TCS under Bolt Looseness Boundary. On the one hand, due to light weight, closed modes, low level, and complicated local vibration of TCS, traditional accelerometer will bring added mass and stiffness to the tested shell [22], which will severely affect the tested frequency and damping results, so laser Doppler vibrometer is used as noncontact response sensor to measure the vibration and frequency information of the shell. On the other hand, different excitation techniques also will result in test error, so the disadvantages of four common vibration excitation devices are compared in Table 6; combining the proposed test method in [23], vibration shaker is finally chosen as excitation source with excitation level being precisely controlled, and test system of modal parameters of TCS under bolt looseness boundary is given in Figure 7. The instruments used in the test are as follow: (I) Polytec PDV-100 laser Doppler vibrometer; (II) king-design EM-1000F vibration shaker systems; (III) LongWei PS-305DM DC power supply; (IV) Aslong JGA25 DC geared motor; (V) $45^{\circ}$ rotation mirror and $45^{\circ}$ fixed mirror; (VI) LMS SCADAS Mobile Front-End and Dell notebook computer.

In these devices, LMS SCADAS Mobile Front-End and Dell notebook computer are responsible for recording and saving response signal from laser Doppler vibrometer. Dell notebook computer with Intel Core i7 $2.93 \mathrm{GHz}$ processor and $4 \mathrm{G}$ RAM is used to operate LMS Test.Lab $10 \mathrm{~B}$ software and store measured data. For the frequency and damping test, sine sweep excitation is conducted with a closed loop control via accelerometer on the countertop of the vibration shaker, and point 1 , point 2 , and point 3 (being $180^{\circ}$ with each other) are used to get response signal by adjusting laser point and average is used as the final results. In this test, 

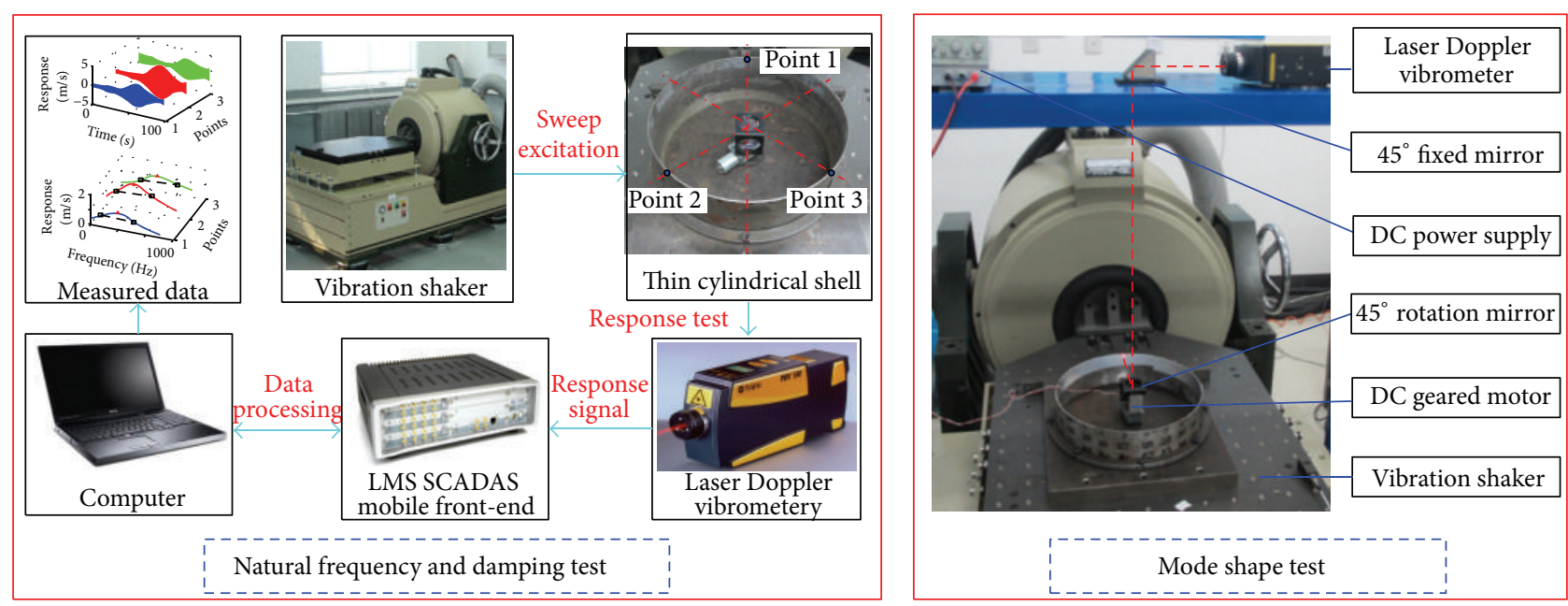

FIGURE 7: Schematic of test system of modal parameters of TCS under bolt looseness boundary.

natural frequency can be precisely determined through each resonant peak in frequency domain, and damping ratio can also be identified by the half-power bandwidth method which is calculated by measuring the bandwidth of the frequency curve (or approximately $3 \mathrm{~dB}$ ) down from the resonant peak. For mode shape test, laser rotating scanning technique is used to get shape results of TCS. Firstly, employ one of natural frequencies of TCS to drive the tested shell under the resonance state by vibration shaker, and then DC power supply is used to provide stable voltage and current for DC geared motor, and the motor is to drive the $45^{\circ}$ rotation mirror to complete a set of cross-sectional scan with $360^{\circ}$ circumferential coverage for the tested shell, and in this way mode shapes data at certain mode can be obtained in a shorter amount of time than traditional test methods.

3.2. Test Method of Modal Parameters of TCS under Bolt Looseness Boundary. In this section, the test procedures of modal parameters and the related identification techniques which are suitable for TCS under bolt looseness boundary are proposed, as seen in the following four key steps.

3.2.1. Accurately Determine Tightening Torque under Fixed Constraint Boundary. Because modal parameters of TCS are closely related to constraint boundary, in actual test, we must ensure that one end of the tested shell is effectively clamped; to this end, a torque wrench is used to determine the level of tightening torque on the M8 bolts of clamping-ring, as seen in Figure 1, and the "preexperiment" is adopted to determine the required tightening torque as well as verify whether or not the tested shell is under fixed constraint boundary. For instance, it should be done at least three times to test natural frequencies, and every time the same level of torque value should be applied on M8 bolts. If test results of the first 3 natural frequencies under three preexperiments are close to each other (e.g., 1 3 Hz), we will regard this torque value as the determined tightening torque under fixed constraint boundary. If the differences between each natural frequency are big, more than $5 \sim 20 \mathrm{~Hz}$, we need to increase torque value and to repeat preexperiments several times.

3.2.2. Measure Modal Parameters of TCS under Fixed Constraint Boundary. This step involves three different measurements and identification techniques. Firstly, using sine sweep excitation by vibration shaker to test natural frequencies of TCS and in order to get precise frequency results, the smallsegment FFT processing technique is employed to deal with the measured sweep signal. The time domain signal involving the 3rd natural frequency of the tested shell is shown in Figure 8(a). If FFT processing technique is directly applied on this sweep signal, we can obtain its frequency spectrum, as seen in Figure 8(b), and the frequency of the response peak is $1024.8 \mathrm{~Hz}$. However, if the whole time of sweep signal can be divided into mall segments, and we conduct FFT on each segment of them (in this example, it is $1 \mathrm{~s}$ with respect to the whole time of $68 \mathrm{~s}$ ), the resulting frequency spectrum, as seen in Figure $8(\mathrm{c})$, is plotted through the combination of the response peak of each segment (also treated with interpolation and smoothing); the frequency value related to the peak is $1025.7 \mathrm{~Hz}$, which is truly accurate result of the 3rd natural frequency. Therefore, for time-dependent sweep signal of TCS, it is necessary to use the small-segment FFT processing technique to accurately get frequency results.

Then, use the half-power bandwidth technique to identify each damping ratio of TCS from the frequency spectrum obtained by small-segment FFT processing technique. Because the resonant peak in the spectrum is already known, we can identify two half-power bandwidth points by measuring the bandwidth of the frequency curve (or approximately $3 \mathrm{~dB}$ ) down from the resonant peak, consequently according to the damping formula to calculate the corresponding damping results based on the MATLAB program. Figure 9 gives time waveform and frequency spectrum for the third natural frequency and damping ratio of TCS at 3 measuring points, and, in order to improve accuracy of frequency and damping results, the final results are obtained by averaging the test results at these points. 


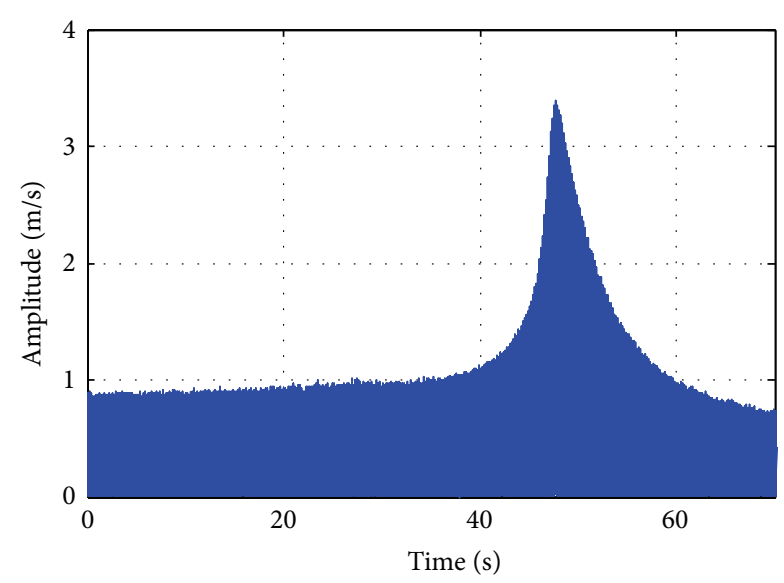

(a) The raw sweep signal

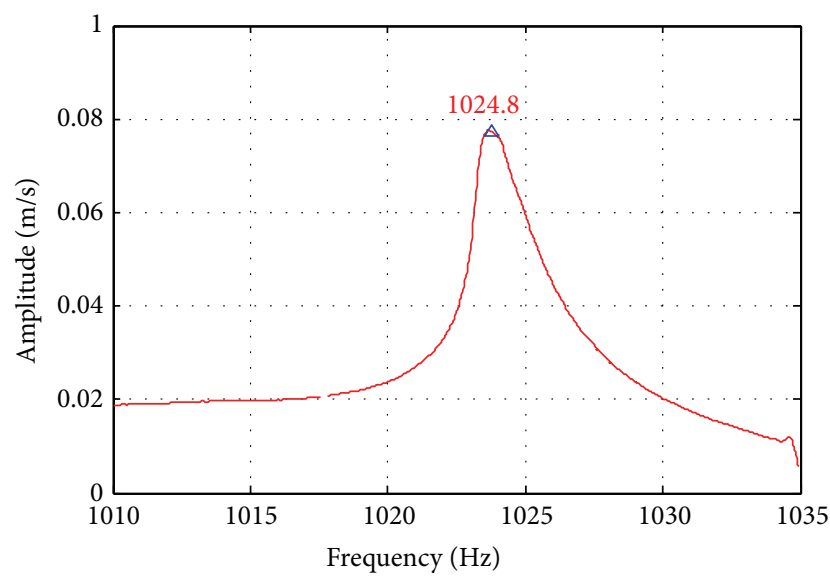

(b) The spectrum by direct FFT

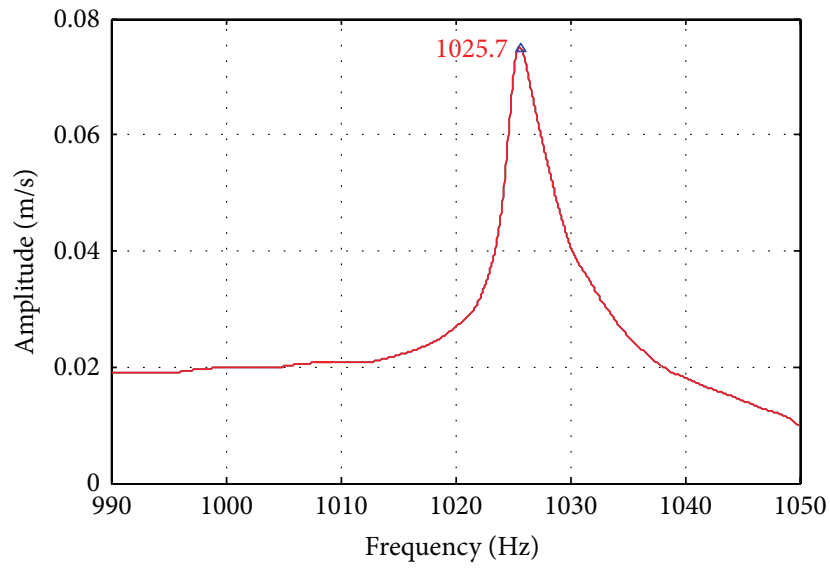

(c) The spectrum by small-segment FFT

FIGURE 8: The 3rd natural frequency of CTCS obtained by different FFT processing techniques.

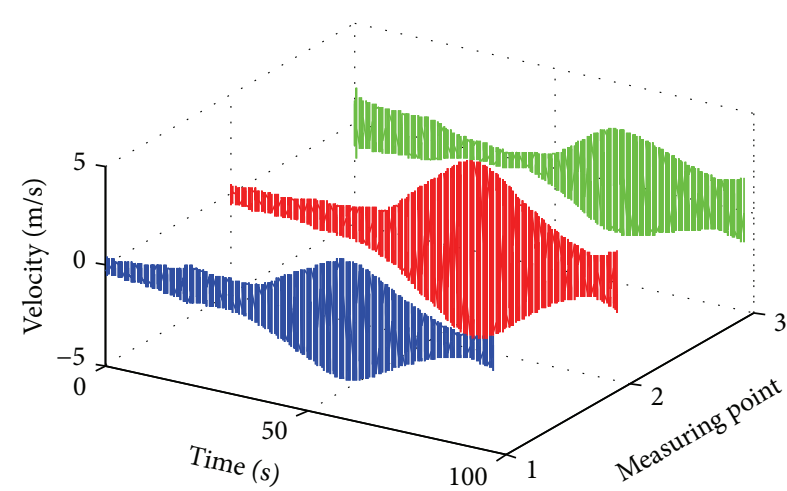

(a) Time waveform

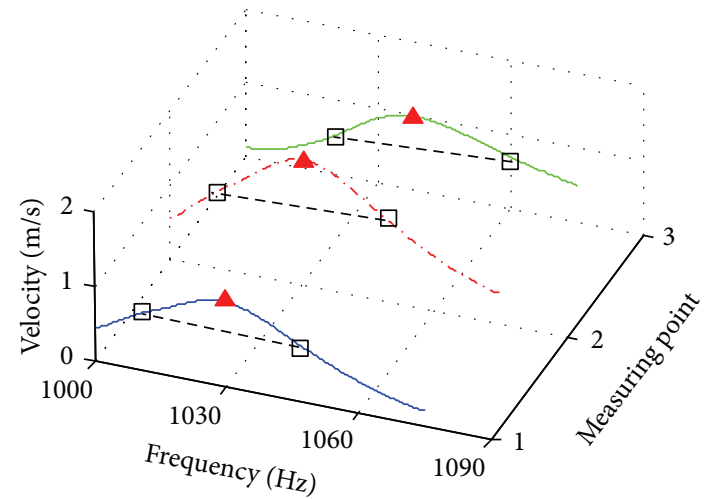

(b) Frequency spectrum

FIGURE 9: Time waveform and frequency spectrum for the third natural frequency and damping ratio of TCS at 3 measuring points.

Finally, use each of natural frequency to excite TCS at resonance state, and gradually obtain each mode shape with obvious reduction in time costs by laser rotating scan method.

3.2.3. Measure Modal Parameters of TCS under BLB with Different Looseness Numbers. After finishing the measurement work under fixed constraint boundary, use torque wrench to loosen bolts on the clamping-ring, according to the sequence of loosening 1 bolt, 2 bolts, 3 bolts, and 4 bolts to conduct modal parameter test, as seen in Figure 10. It should be noted that the excitation level and the position of the three measuring points must be the same as the ones under fixed constraint boundary, and the same test methods, such as the small-segment FFT processing technique, the half-power 


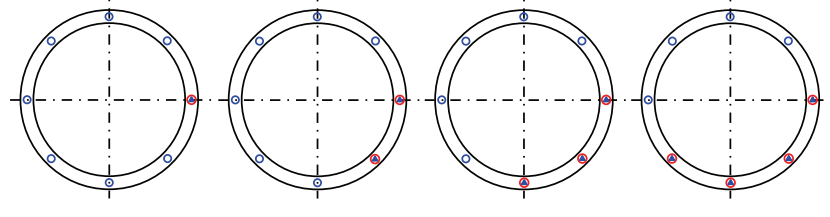

FIgURE 10: Schematic of bolt looseness sequence.

bandwidth technique, and the laser rotating scan technique, are employed to get natural frequencies, mode shapes, and damping ratios of TCS under BLB with different looseness numbers.

3.2.4. Measure Modal Parameters of TCS under BLB with Different Looseness Levels. In this step, firstly it is needed to restore boundary condition to the fixed state, so the same level of tightening torque which is determined by the preexperiment in the first step is again used to tighten eight M8 bolts on the clamping-ring. Then, set the torque value to $75 \%, 50 \%$, and $25 \%$ of this tightening torque, according to the sequence of $25 \%$ looseness, $50 \%$ looseness, and $75 \%$ looseness to carry out experimental test. Applying the same excitation level and using the same test method, we can get the corresponding frequency, damping, and shape results of TCS under BLB with different looseness levels.

\section{The Influence Analysis of Modal Parameters of TCS under Bolt Looseness Boundary}

In this section, on the basis of both theoretical and experimental results, that is, the simulation results calculated by FEM in Section 2 and the accurate measured data obtained by the test system and test method in Section 3, the influence on natural frequencies, mode shapes, and damping ratios of TCS under two types of bolt looseness boundaries is analyzed and discussed in detail.

4.1. Test Results of Modal Parameters of TCS under BLB with Different Looseness Numbers. According to the proposed test method and procedures in Section 3, point 1, point 2, and point 3 are used as the response points, which are $180^{\circ}$ with each other and in the same cross section of the shell the axial distance from this section to free end of TCS is about $5 \mathrm{~mm}$, as seen in Figure 7 . For the natural frequency and damping test, the following setups and parameters are chosen: (I) excitation level of $1 \mathrm{~g}$; (II) sweep rate of $1 \mathrm{~Hz} / \mathrm{s}$; (III) frequency resolution of $0.125 \mathrm{~Hz}$; (IV) Hanning window for sweep response signal with upward sweep direction; (V) frequency range of $0-2048 \mathrm{~Hz}$. For the mode shape test, the following setups and parameters are chosen: (I) excitation level of $1 \tilde{\mathrm{g}} 3 \mathrm{~g}$; (II) frequency resolution of $0.125 \mathrm{~Hz}$; (III) rectangular window for stable response signal; (IV) sampling frequency of $12800 \mathrm{~Hz}$; (V) rotated scan speed of $2 \mathrm{r} / \mathrm{min}$. Besides, the first 8 mode shapes of TCS are obtained in the test, and each mode shape is assembled from two sets of cross-sectional scans; one is in the section which includes point 1 , point 2 , and point 3 and the other is about $25 \mathrm{~mm}$ to

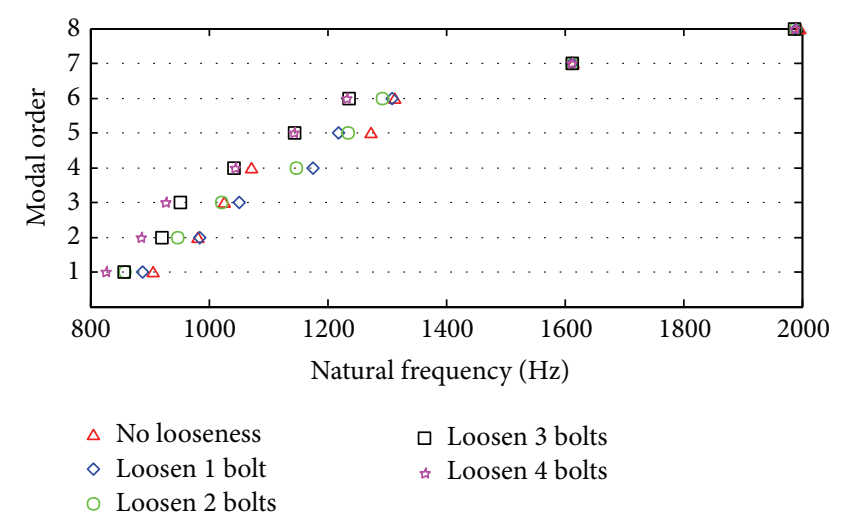

FIGURE 11: Scattergram of natural frequencies of TCS under BLB with different looseness numbers.

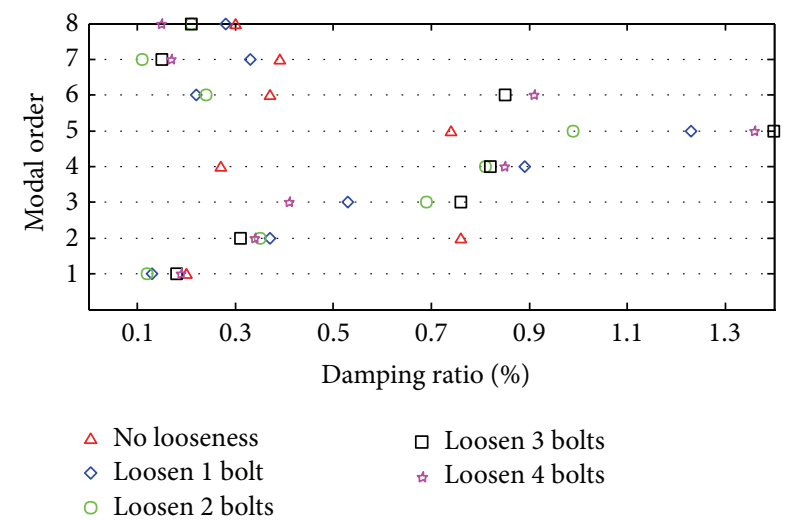

FIGURE 12: Scattergram of damping ratios of TCS under BLB with different looseness numbers.

the clamped end of the shell (restricted by the height of DC geared motor itself but do not affect the test results when the number of axial half-waves $m=1$ ).

The measured frequency, damping, and shape results under BLB with different looseness numbers are listed in Tables 7, 8, and 9, respectively. Besides, in order to clearly describe the effect degree and trend of the shell under different bolt looseness boundaries, the scattergrams of natural frequencies and damping ratios of TCS related to different bolt looseness number are also given, as shown in Figures 11 and 12, and Figure 13 gives the relations between natural frequency and mode shape under BLB with different looseness numbers.

\subsection{The Influence Analysis of Modal Parameters under BLB with Different Looseness Numbers}

4.2.1. The Influence on Natural Frequencies of TCS. From Table 7 and Figure 11, the following can be found. (I) For the most modes of TCS, the increase of bolt looseness number would reduce the natural frequencies of TCS, but if only 1 bolt is loosened, the decreased degree of natural frequencies of TCS is not obvious. With the increase of bolt looseness number, the decreased degree of frequency values 
TABLE 7: Natural frequencies of TCS under BLB with different looseness numbers.

\begin{tabular}{|c|c|c|c|c|c|c|c|c|c|}
\hline $\begin{array}{l}\text { Modal } \\
\text { order }\end{array}$ & $\begin{array}{c}\text { No looseness } \\
A \\
(\mathrm{~Hz})\end{array}$ & $\begin{array}{c}\text { Loosen } \\
1 \text { bolt } \\
B \\
(\mathrm{~Hz}) \\
\end{array}$ & $\begin{array}{c}\text { Effect degree } \\
(B-A) / A \\
(\%)\end{array}$ & $\begin{array}{c}\text { Loosen } \\
2 \text { bolts } \\
\mathrm{C} \\
(\mathrm{Hz}) \\
\end{array}$ & $\begin{array}{c}\text { Effect degree } \\
(C-A) / A \\
(\%)\end{array}$ & $\begin{array}{c}\text { Loosen } \\
3 \text { bolts } \\
D \\
(\mathrm{~Hz}) \\
\end{array}$ & $\begin{array}{c}\text { Effect degree } \\
(D-A) / A \\
(\%)\end{array}$ & $\begin{array}{c}\text { Loosen } \\
4 \text { bolts } \\
E \\
(\mathrm{~Hz}) \\
\end{array}$ & $\begin{array}{c}\text { Effect } \\
\text { degree } \\
(E-A) / A \\
(\%)\end{array}$ \\
\hline 1 & 906.3 & 888.7 & -1.9 & 857.9 & -5.3 & 857.5 & -5.4 & 827.9 & -8.6 \\
\hline 2 & 980.8 & 980.0 & 0 & 947.1 & -3.4 & 920.6 & -6.1 & 886.5 & -9.6 \\
\hline 3 & 1025.7 & 1051.2 & 2.5 & 1021.0 & -0.5 & 951.8 & -7.2 & 927.9 & -9.5 \\
\hline 4 & 1072.3 & 1175.3 & 9.6 & 1147.0 & 7.0 & 1042.2 & -2.8 & 1045.6 & -2.5 \\
\hline 5 & 1274.0 & 1218.6 & -4.3 & 1235.0 & -3.1 & 1145.1 & -10.1 & 1143.8 & -10.2 \\
\hline 6 & 1312.8 & 1309.1 & -0.3 & 1292.6 & -1.5 & 1236.2 & -5.8 & 1233.3 & -6.1 \\
\hline 7 & 1613.8 & 1612.2 & -0.1 & 1613.0 & 0 & 1613.2 & 0 & 1612.3 & -0.1 \\
\hline 8 & 1996.3 & 1990.2 & -0.3 & 1989.1 & -0.4 & 1988.0 & -0.4 & 1989.6 & -0.3 \\
\hline
\end{tabular}

TABLE 8: Damping ratios of TCS under BLB with different looseness numbers.

\begin{tabular}{|c|c|c|c|c|c|c|c|c|c|}
\hline $\begin{array}{l}\text { Modal } \\
\text { order }\end{array}$ & $\begin{array}{c}\text { No looseness } \\
A \\
(\%)\end{array}$ & $\begin{array}{c}\text { Loosen } \\
1 \text { bolt } \\
B \\
(\%)\end{array}$ & $\begin{array}{c}\text { Effect degree } \\
(B-A) / A \\
(\%)\end{array}$ & $\begin{array}{c}\text { Loosen } \\
2 \text { bolts } \\
C \\
(\%)\end{array}$ & $\begin{array}{c}\text { Effect degree } \\
(C-A) / A \\
(\%)\end{array}$ & $\begin{array}{c}\text { Loosen } \\
3 \text { bolts } \\
D \\
(\%)\end{array}$ & $\begin{array}{c}\text { Effect degree } \\
(D-A) / A \\
(\%)\end{array}$ & $\begin{array}{c}\text { Loosen } \\
4 \text { bolts } \\
E \\
(\%)\end{array}$ & $\begin{array}{c}\text { Effect degree } \\
(E-A) / A \\
(\%)\end{array}$ \\
\hline 1 & 0.20 & 0.13 & -35.0 & 0.12 & -40.0 & 0.18 & -10.0 & 0.19 & -5.0 \\
\hline 2 & 0.76 & 0.37 & -51.3 & 0.35 & -53.9 & 0.31 & -59.2 & 0.34 & -55.3 \\
\hline 3 & 1.14 & 0.53 & -53.5 & 0.69 & -39.5 & 0.76 & -33.3 & 0.41 & -64.0 \\
\hline 4 & 0.27 & 0.89 & 229.6 & 0.81 & 200.0 & 0.82 & 203.7 & 0.85 & 214.8 \\
\hline 5 & 0.74 & 1.23 & 66.2 & 0.99 & 33.8 & 1.40 & 89.2 & 1.36 & 83.8 \\
\hline 6 & 0.37 & 0.22 & -40.5 & 0.24 & -35.1 & 0.85 & 129.7 & 0.91 & 145.9 \\
\hline 7 & 0.39 & 0.33 & -15.4 & 0.11 & -71.8 & 0.15 & -61.5 & 0.17 & -56.4 \\
\hline 8 & 0.30 & 0.28 & -6.7 & 0.21 & -30.0 & 0.21 & -30.0 & 0.15 & -50.0 \\
\hline
\end{tabular}

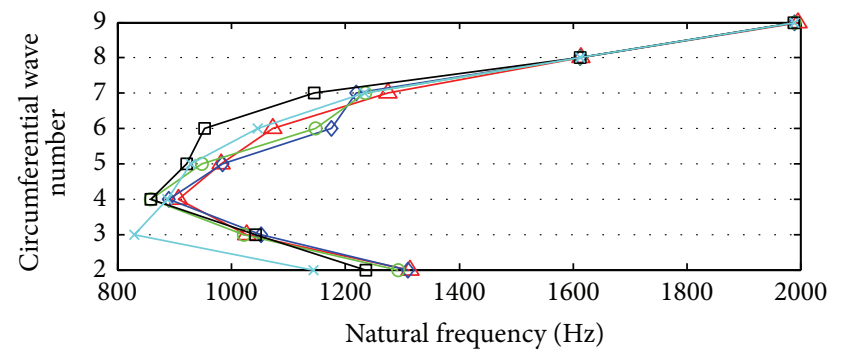

$\begin{array}{ll}\triangle \text { No looseness } & \square \text { Loosen } 3 \text { bolts } \\ \diamond \text { Loosen } 1 \text { bolt } & \times \text { Loosen } 4 \text { bolts } \\ - \text { Loosen } 2 \text { bolts } & \end{array}$

FIGURE 13: The relation between natural frequency and mode shape under BLB with different looseness numbers.

is becoming more obvious than the ones under the fixed state. For example, the 1st and 2nd natural frequencies are decreased nearly to $10 \%$. (II) The increase of bolt looseness number would also result in the decrease of high order of natural frequencies, but the decreased degree is very small. Taking the 7th and 8th natural frequencies for example, they only decrease to $0.4 \%$ compared with the ones under the fixed state. Therefore, it can be concluded that high order natural frequencies are basically not affected by BLB with different looseness numbers. (III) For some modes, their natural frequencies will go up when the lower looseness numbers are reached (loosening 1 2 bolts); for example, the maximum increased degree of the $3 \mathrm{rd}$ and the 4 th natural frequencies of TCS can increase to $9.6 \%$. Because the corresponding shape results are not changed, the increased frequency values might be caused by the changes of nonlinear stiffness in bolt looseness positions.

4.2.2. The Influence on Damping Ratios of TCS. From Table 8 and Figure 12, the following can be found. (I) For most modes of TCS, bolt looseness would reduce the damping of TCS. For example, for different bolt looseness number, the decreased range of damping results is about $5 \% \sim 70 \%$, but the decreased degree of damping is not proportional to the bolt looseness number. (II) For a small part of modes of TCS, the damping results will rise with the increase of bolt looseness number, especially when the looseness number goes up to some extent, for example, loosening $3 \sim 4$ bolts; the resulting damping values related to the 4 th and the 6 th mode are nearly $1 \sim 2$ times larger than the ones under no loose condition, which may be largely caused by the changes of mode shape or increased interface friction in bolt looseness positions. 
TABLE 9: Mode shapes of TCS under BLB with different looseness numbers.

Modal
order

4.2.3. The Influence on Mode Shapes of TCS. From Table 9 and Figure 13, the following can be found. (I) When bolt looseness number is little, such as loosening 1 or 2 bolts, the resulting shapes of TCS can hardly be changed. (II) With the increase of bolt looseness number, low order mode shapes of TCS are varied at different levels, but for high order mode shapes, such as the 7 th and the 8th shape results, they are unchanged and still the same as the ones under no loose condition. (III) The changing trend of natural frequencies with mode shapes is constant when the number of axial half-waves $m=1$, which shows that frequency values firstly decline and then rise with the increase of the number of circumferential waves $n$, and usually frequency values related to $n>8$ are higher than $n=$ $2 \sim 7$, and this frequency-shape relation agrees well with the result calculated by FEM.

4.3. Test Results of Modal Parameters of TCS under BLB with Different Looseness Levels. Similarly, based on the same test system and test method, modal parameters of TCS under different bolt looseness levels can be obtained. The measured frequency, damping, and shape results under BLB with different looseness levels are listed in Tables 10, 11, and 12 , respectively. Besides, in order to clearly describe the effect degree and trend of the shell under different bolt looseness boundaries, the scattergrams of natural frequencies and damping ratios of TCS related to different bolt looseness number are also given, as shown in Figures 14 and 15, and Figure 16 gives the relations between natural frequency and mode shape under BLB with different looseness levels.

\subsection{The Influence Analysis of Modal Parameters under BLB with Different Looseness Levels}

4.4.1. The Influence on Natural Frequencies of TCS. From Table 10 and Figure 14, it can be found that: (I) For the most modes of TCS, the increase of bolt looseness level would reduce the natural frequencies of TCS, but if looseness level is small, the decreased degree of natural frequencies of TCS is not obvious. For example, the resulting natural frequencies 
TABLE 10: Natural frequencies of TCS under BLB with different looseness levels.

\begin{tabular}{|c|c|c|c|c|c|c|c|}
\hline $\begin{array}{l}\text { Modal } \\
\text { order }\end{array}$ & $\begin{array}{c}\text { No looseness } \\
A \\
(\mathrm{~Hz})\end{array}$ & $\begin{array}{c}25 \% \\
\text { looseness } \\
B \\
(\mathrm{~Hz})\end{array}$ & $\begin{array}{c}\text { Effect degree } \\
(B-A) / A \\
(\%)\end{array}$ & $\begin{array}{c}50 \% \\
\text { looseness } \\
C \\
(\mathrm{~Hz})\end{array}$ & $\begin{array}{c}\text { Effect degree } \\
(C-A) / A \\
(\%)\end{array}$ & $\begin{array}{c}75 \% \\
\text { looseness } \\
D \\
(\mathrm{~Hz})\end{array}$ & $\begin{array}{c}\text { Effect degree } \\
(D-A) / A \\
(\%)\end{array}$ \\
\hline 1 & 906.3 & 904.6 & -0.2 & 887.8 & -2.0 & 806.7 & -11.0 \\
\hline 2 & 980.8 & 978.2 & -0.3 & 915.4 & -6.7 & 848.8 & -13.5 \\
\hline 3 & 1025.7 & 1011.1 & -1.4 & 980.1 & -4.4 & 951.5 & -7.2 \\
\hline 4 & 1072.3 & 1062.3 & -0.9 & 1072.0 & 0 & 1010.7 & -5.7 \\
\hline 5 & 1274.0 & 1267.0 & -0.5 & 1268.3 & -0.4 & 1279.1 & 0.4 \\
\hline 6 & 1312.8 & 1309.3 & -0.3 & 1310.6 & -0.2 & 1319.6 & 0.5 \\
\hline 7 & 1613.8 & 1613.3 & 0 & 1612.4 & -0.1 & 1608.8 & -0.3 \\
\hline 8 & 1996.3 & 1992.4 & -0.2 & 1990.8 & -0.3 & 1987.9 & -0.4 \\
\hline
\end{tabular}

TABLE 11: Damping ratios of TCS under BLB with different looseness levels.

\begin{tabular}{|c|c|c|c|c|c|c|c|}
\hline $\begin{array}{l}\text { Modal } \\
\text { order }\end{array}$ & $\begin{array}{c}\text { No looseness } \\
A \\
(\mathrm{~Hz})\end{array}$ & $\begin{array}{c}25 \% \\
\text { looseness } \\
B \\
(\mathrm{~Hz}) \\
\end{array}$ & $\begin{array}{c}\text { Effect degree } \\
(B-A) / A \\
(\%)\end{array}$ & $\begin{array}{c}50 \% \\
\text { looseness } \\
C \\
(\mathrm{~Hz}) \\
\end{array}$ & $\begin{array}{c}\text { Effect degree } \\
(C-A) / A \\
(\%)\end{array}$ & $\begin{array}{c}75 \% \\
\text { looseness } \\
D \\
(\mathrm{~Hz}) \\
\end{array}$ & $\begin{array}{c}\text { Effect degree } \\
(D-A) / A \\
(\%)\end{array}$ \\
\hline 1 & 0.20 & 0.12 & -40.0 & 0.16 & -20.0 & 0.18 & -10.0 \\
\hline 2 & 0.76 & 0.37 & -51.3 & 0.17 & -77.6 & 0.53 & -30.3 \\
\hline 3 & 1.14 & 1.02 & -10.5 & 0.51 & -55.3 & 1.03 & -9.6 \\
\hline 4 & 0.27 & 0.36 & 33.3 & 0.33 & 22.2 & 0.72 & 166.7 \\
\hline 5 & 0.74 & 0.85 & 14.9 & 0.84 & 13.5 & 0.88 & 18.9 \\
\hline 6 & 0.37 & 0.24 & -35.1 & 0.25 & -32.4 & 0.95 & 156.8 \\
\hline 7 & 0.39 & 0.3 & -23.1 & 0.19 & -51.3 & 0.17 & -56.4 \\
\hline 8 & 0.30 & 0.13 & -56.7 & 0.15 & -50.0 & 0.17 & -43.3 \\
\hline
\end{tabular}

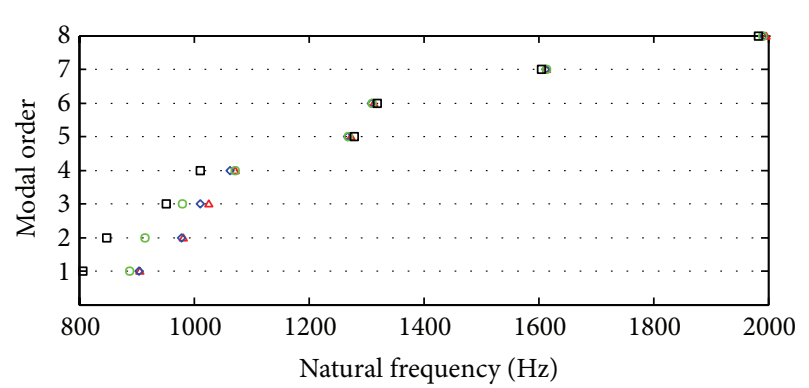

$\begin{array}{ll}\triangle \text { No looseness } & \circ 50 \% \text { looseness } \\ \diamond 25 \% \text { looseness } & \square 75 \% \text { looseness }\end{array}$

FIGURE 14: Scattergram of natural frequencies of TCS under BLB with different looseness levels.

are decreased from $0.2 \%$ to $1.4 \%$ under looseness level of $25 \%$ compared with the ones under the fixed state. (II) With the increase of bolt looseness level, the decreased degree of low order frequency values becomes more obvious, and taking the 1st and 2nd natural frequencies for example, they basically decrease from $11 \%$ to $13.5 \%$ compared with the ones under the fixed state. (III) The increase of bolt looseness level would also result in the decrease of high order of natural frequencies, but the decreased degree is very small. Taking the 7 th and 8 th natural frequencies for an example, the maximum of the decreased frequency results is about $0.4 \%$ compared with the ones under the fixed state. Therefore, it can be concluded that

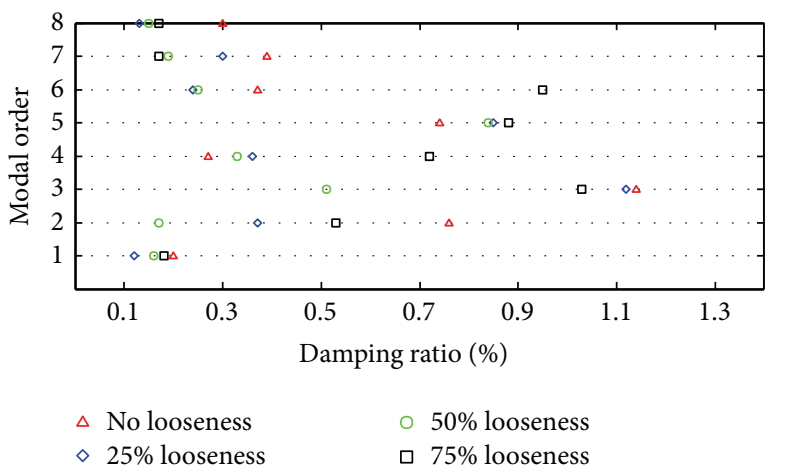

FIGURE 15: Scattergram of damping ratios of TCS under BLB with different looseness levels.

high order natural frequencies are basically not affected by BLB with different looseness levels. (IV) For some modes, their natural frequencies will go up slightly when the higher looseness level is reached (75\% looseness). However, the maximum increased degree of the 5th and the 6th natural frequencies of TCS increases less than $0.5 \%$, so basically we can ignore the effect of increased frequency values, which might be caused by the changes of nonlinear stiffness in bolt looseness positions.

4.4.2. The Influence on Damping Ratios of TCS. From Table 11 and Figure 15, it can be found that: (I) For most modes 
TABLE 12: Mode shapes of TCS under BLB with different looseness levels.

Modal
order

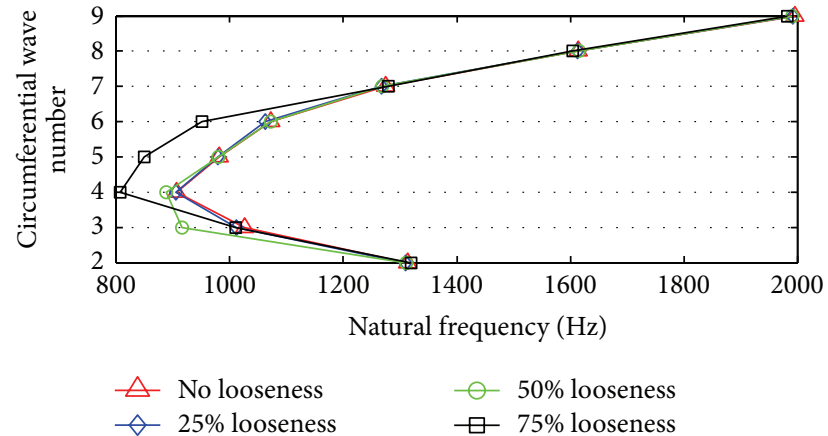

FIGURE 16: The relation between natural frequency and mode shape under BLB with different looseness levels.

of TCS, bolt looseness would reduce the damping of TCS. For example, for different bolt looseness level, the decreased range of damping results is obvious and is within $10 \% \sim 78 \%$, but the decreased degree of damping is not proportional to the bolt looseness level. (II) For a small part of modes of TCS, the damping results will rise with the increase of bolt looseness level, especially when the looseness level goes up to some extent; for example, when looseness level of $75 \%$ is reached, the resulting damping values related to the 4 th and the 6 th mode are nearly 1.5 times larger than the ones under no loose condition, which may be caused by the changes of mode shape or increased interface friction in bolt looseness positions.

4.4.3. The Influence on Mode Shapes of TCS. From Table 12 and Figure 16, it can be found that: (I) When bolt looseness level is relatively low, for example, when it is less than $25 \%$, the resulting shapes of TCS can hardly be changed. (II) With the increase of bolt looseness level, low order mode shapes of TCS are varied, but for the intermediate and high order mode shapes, such as the 5 th, the 6 th, the 7 th, and the 8 th shape results, they are unchanged and are still the same as the ones under no loose condition. (III) Both natural frequencies and mode shapes of TCS would be changed under different bolt looseness levels, but the changing trend of natural frequencies with mode shapes is constant when the number of axial 
half-waves $m=1$, which shows that frequency values firstly decline and then rise with the increase of the number of circumferential waves $n$, and usually frequency values related to $n>8$ are higher than $n=2 \sim 7$, and this frequency-shape relation agrees well with the result calculated by FEM.

\section{Conclusions}

This research combines theory with experiment to investigate the influence on modal parameters of TCS under bolt looseness boundary. Based on the analysis and experimental results, the following conclusions can be drawn as follows.

(1) Finite element method is adopted to roughly master vibration characteristics of shell structure, and theoretical analysis results of natural frequency and mode shape provide an important reference for experimental investigation on the influence on modal parameters of bolt constrained shell under different looseness boundaries.

(2) Test system and method under bolt looseness boundary is proposed to accurately measure modal parameters of TCS, and the following measurements and identification techniques are used to get precise frequency, damping, and shape results: (I) noncontact laser Doppler vibrometer and vibration shaker with excitation level being precisely controlled are used in the test system; (II) "preexperiment" is adopted to determine the required tightening torque and verify fixed constraint boundary; (III) the small-segment FFT processing technique is employed to accurately measure nature frequency; (IV) laser rotating scanning technique is used to get shape results with high efficiency.

(3) The influence on modal parameters of TCS under different bolt looseness numbers and different bolt looseness levels is analyzed in detail. It can be found that bolt looseness boundary can significantly affect frequency and damping results which might be caused by changes of nonlinear stiffness and damping and in bolt looseness positions. However, high order natural frequencies and mode shapes are still the same as the ones under no loose condition, and the changing trend of natural frequencies with mode shapes is constant when the number of axial half-waves $m=1$, which agrees well with the result calculated by finite element method. Besides, bolt looseness would reduce the damping for most modes of TCS, but the decreased degree of damping is not proportional to the bolt looseness number or the bolt looseness level.

\section{Conflict of Interests}

The authors declare that there is no conflict of interests regarding the publication of this paper.

\section{Acknowledgments}

This study was supported by the National Natural Science Foundation of China Grant no. 51505070, the National Natural Science Foundation of China Grant no. 51375079, and the National Key Scientific Instrument and Equipment Development Project of China Grant no. 2013YQ470765.

\section{References}

[1] A. W. Leissa, Vibrations of Shells, Acoustical Society of America, Columbus, Ohio, USA, 1973.

[2] K. H. Ip, W. K. Chan, P. C. Tse, and T. C. Lai, "Vibration analysis of orthotropic thin cylindrical shells with free ends by the rayleigh-ritz method," Journal of Sound and Vibration, vol. 195, no. 1, pp. 117-135, 1996.

[3] M. Amabili, "Free vibration of a fluid-filled circular cylindrical shell with lumped masses attached, using the receptance method," Shock and Vibration, vol. 3, no. 3, pp. 159-167, 1996.

[4] C. T. Loy, K. Y. Lam, and C. Shu, "Analysis of cylindrical shells using generalized differential quadrature," Shock and Vibration, vol. 4, no. 3, pp. 193-198, 1997.

[5] A. Farshidianfar, M. H. Farshidianfar, M. J. Crocker, and W. O. Smith, "Vibration analysis of long cylindrical shells using acoustical excitation," Journal of Sound and Vibration, vol. 330, no. 14, pp. 3381-3399, 2011.

[6] R. L. Goldman, "Mode shapes and frequencies of clampedclamped cylindrical shells," AIAA Journal, vol. 12, no. 12, pp. 1755-1756, 1974.

[7] D. J. Ewins, Modal Testing: Theory and Practice, Research Studies Press, Latchworth, UK, 1984.

[8] B. Peeters, H. D. V. Auweraer, P. Guillaume, and J. Leuridan, "The PolyMAX frequency-domain method: a new standard for modal parameter estimation?" Shock and Vibration, vol. 11, no. 3-4, pp. 395-409, 2004.

[9] L. H. Sobel, "Effects of boundary conditions on the stability of cylinders subject to lateral and axial pressures," The AIAA Journal, vol. 2, no. 8, pp. 1437-1440, 1964.

[10] S. Sun, S. Chu, and D. Cao, "Vibration characteristics of thin rotating cylindrical shells with various boundary conditions," Journal of Sound and Vibration, vol. 331, no. 18, pp. 4170-4186, 2012.

[11] H. T. Wang, "Casing stiffness analysis of pretightening force bolt joint," Aeroengine, vol. 36, no. 3, pp. 32-35, 2010.

[12] Y.-D. Kwon, H.-W. Kwon, J.-H. Hwangbo, and S.-H. Jang, "Finite element modeling for static and dynamic analysis of structures with bolted joint," Key Engineering Materials, vol. 306-308, pp. 547-552, 2006.

[13] L. Liu, Z. Sun, M. Miao, and P. Li, "Fracture analysis of connection bolts of aero-engine," Failure Analysis and Prevention, vol. 7, no. 4, pp. 244-247, 2012.

[14] K. Forsberg, "Influence of boundary conditions on the modal characteristics of thin cylindrical shells," AIAA Journal, vol. 2, no. 12, pp. 2150-2157, 1964.

[15] T. Koga, "Effect of boundary conditions on the free vibrations of circular cylindrical shells," AIAA journal, vol. 26, no. 11, pp. 1387-1394, 1988.

[16] A. H. Sofiyev, S. N. Keskin, and A. H. Sofiyev, "Effects of elastic foundation on the vibration of laminated non-homogeneous orthotropic circular cylindrical shells," Shock and Vibration, vol. 11, no. 2, pp. 89-101, 2004.

[17] B. Liang and W. Zhang, "Two types of optimization of cylindrical shell on deformation," Journal of Ship Mechanics, vol. 9, no. 4, pp. 98-102, 2005.

[18] G. M. Dong, J. Chen, X. Y. Lei et al., "Study on diagnosing attachment bolt looseness in missile clamping support," Journal of Vibration Measurement \& Diagnosis, vol. 25, no. 3, pp. 98-102, 2005. 
[19] G. M. Dong, J. Chen, and N. Zhang, "Experimental study on monitoring the attachment bolt looseness in a clamping support structure model," in Engineering Asset Management: Proceedings of the 1st World Congress on Engineering Asset Management (WCEAM) 11-14 July 2006, pp. 964-970, Springer, London, UK, 2006.

[20] H. Zhou, W. Li, B. Lv, and W. L. Li, "Free vibrations of cylindrical shells with elastic-support boundary conditions," Applied Acoustics, vol. 73, no. 8, pp. 751-756, 2012.

[21] S. P. Sun, Study on dynamic characteristics of rotating thin-walled cylindrical shells [Ph.D. thesis], Harbin Institute of Technology, 2013.

[22] M. Amabili, R. Garziera, and A. Negri, "Experimental study on large-amplitude vibrations of water-filled circular cylindrical shells," Journal of Fluids and Structures, vol. 16, no. 2, pp. 213227, 2002.

[23] H. Li, W. Sun, Z. Xu, and Q. K. Han, "An experimental method of laser rotating canning to measure mode shape of constrained thin cylindrical shell," Journal of Vibration and Shock, vol. 33, no. 16, pp. 155-159, 2014. 


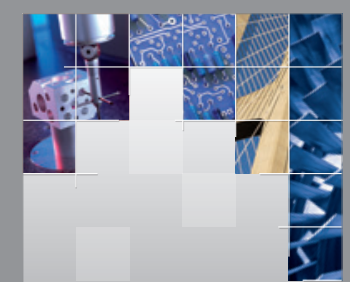

\section{Enfincering}
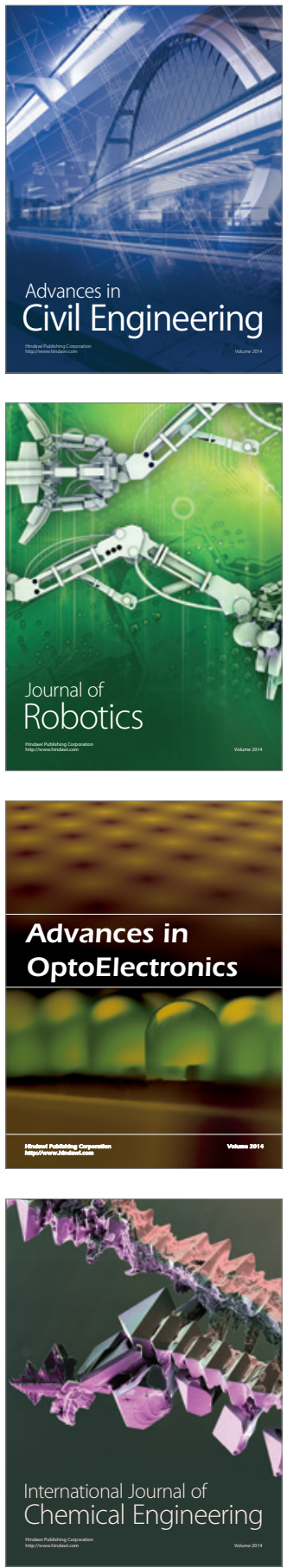

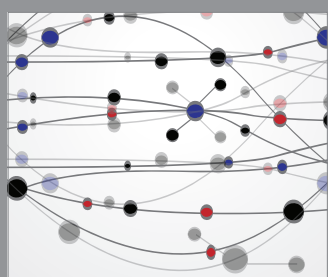

The Scientific World Journal

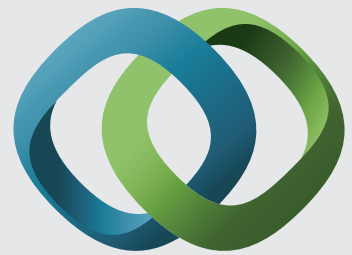

\section{Hindawi}

Submit your manuscripts at

http://www.hindawi.com
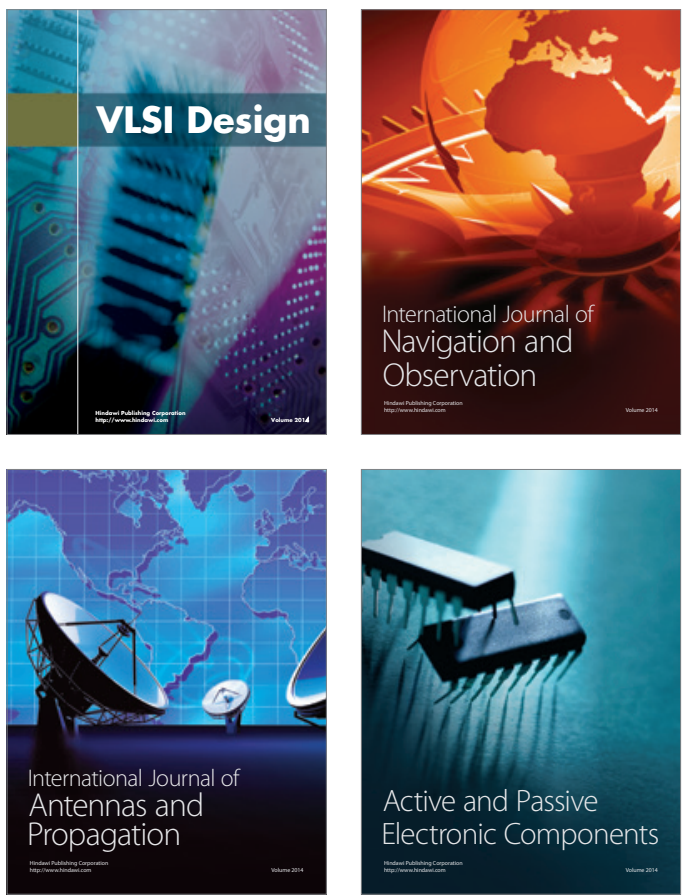
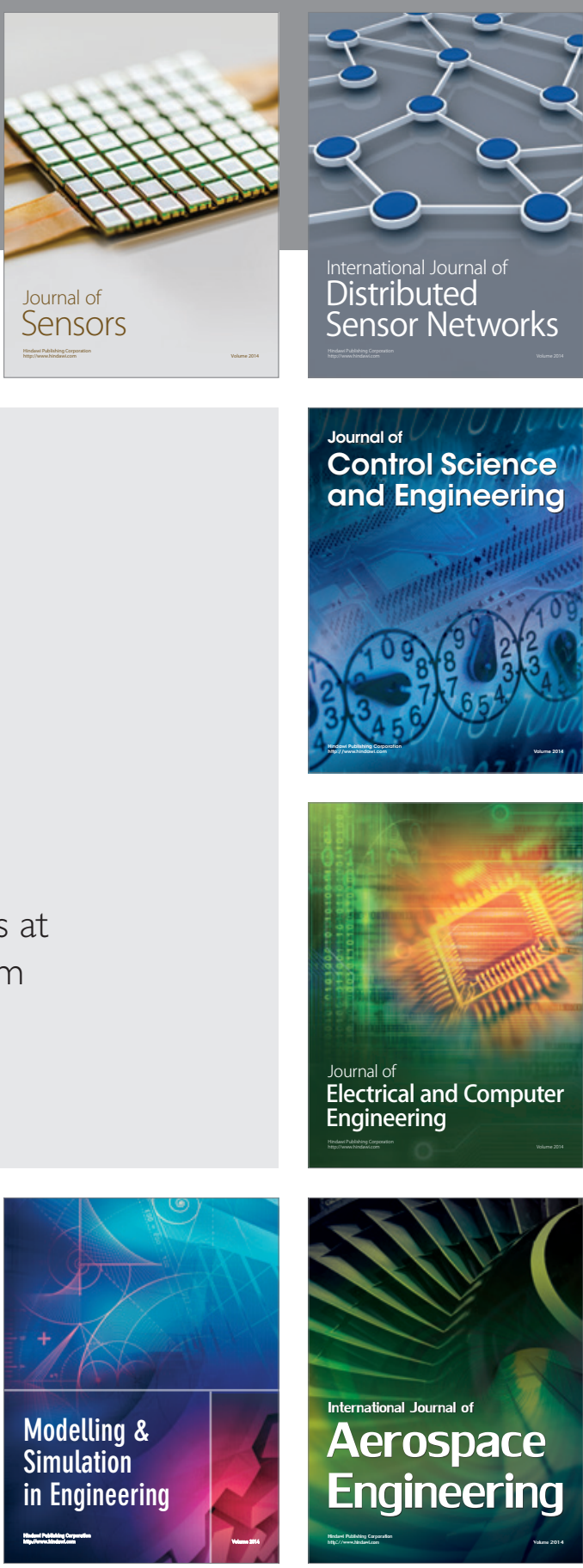

International Journal of

Distributed

Sensor Networks

Journal of

Control Science

and Engineering
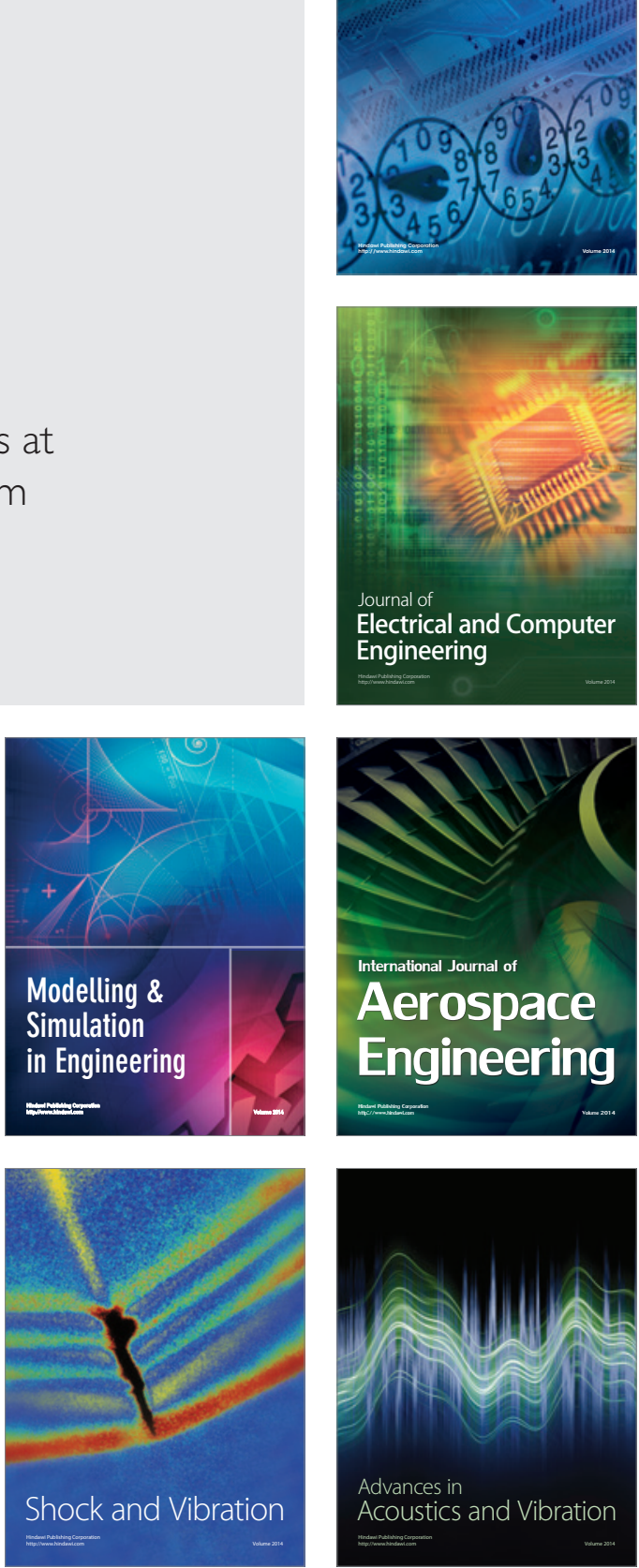